\title{
Anticoagulant treatment for acute pulmonary embolism: a pathophysiology- based clinical approach
}

\author{
Giancarlo Agnelli and Cecilia Becattini
}

Affiliation:

Internal and Cardiovascular Medicine, Stroke Unit, University of Perugia, Perugia, Italy.

\section{Correspondence:}

Giancarlo Agnelli, Internal and Cardiovascular Medicine-Stroke Unit, University of Perugia, V. G. Dottori 1 , Perugia, Italy.

E-mail: giancarlo.agnellidunipg.it

ABSTRACT The management of patients with acute pulmonary embolism is made challenging by its wide spectrum of clinical presentation and outcome, which is mainly related to patient haemodynamic status and right ventricular overload. Mechanical embolic obstruction and neurohumorally mediated pulmonary vasoconstriction are responsible for right ventricular overload. The pathophysiology of acute pulmonary embolism is the basis for risk stratification of patients as being at high, intermediate and low risk of adverse outcomes. This risk stratification has been advocated to tailor clinical management according to the severity of pulmonary embolism.

Anticoagulation is the mainstay of the treatment of acute pulmonary embolism. New direct oral anticoagulants, which are easier to use than conventional anticoagulants, have been compared with conventional anticoagulation in five randomised clinical trials including $>11000$ patients with pulmonary embolism. Patients at high risk of pulmonary embolism (those with haemodynamic compromise) were excluded from these studies. Direct oral anticoagulants have been shown to be as effective and at least as safe as conventional anticoagulation in patients with pulmonary embolism without haemodynamic compromise, who are the majority of patients with this disease. Whether these agents are appropriate for the acute-phase treatment of patients at intermediate-high risk pulmonary embolism (those with both right ventricle dysfunction and injury) regardless of any risk stratification remains undefined.

@ERSpublications

New oral anticoagulants are efficacious and safe in haemodynamically stable patients with acute pulmonary embolism http://ow.ly/I2iP5 


\section{Introduction}

Pulmonary embolism is a common disease with an estimated incidence of 1-2 per 1000 annually in the general population [1]. Anticoagulation is the mainstay for the treatment of acute pulmonary embolism [2]. For several decades, low-molecular-weight heparin or unfractionated heparin followed by oral vitamin $\mathrm{K}$ antagonists have been the conventional treatment for pulmonary embolism.

Direct oral anticoagulants have recently been evaluated as an alternative to conventional anticoagulation for the treatment of venous thromboembolism [3]. All but one of the phase III studies with the new oral agents included both patients with deep vein thrombosis and patients with pulmonary embolism. The risk of early in-hospital death in patients with pulmonary embolism ranges from $1 \%$ to $>30 \%$, depending on clinical presentation, and is higher than in patients with deep vein thrombosis [4-6]. This requires the availability of efficacy and safety data for the new oral agents across the spectrum of severity of pulmonary embolism.

This article focuses on currently available evidence for the potential use of new anticoagulants in patients with acute pulmonary embolism, taking into account the pathophysiology of this disease and its link to the risk of in-hospital death.

\section{Pathophysiology of acute pulmonary embolism}

The arrival of emboli into the pulmonary circulation can induce acute pulmonary hypertension and acute right heart overload, which could potentially result in right ventricular failure and, in some patients, right ventricular infarction [7]. This condition is diagnosed at autopsy in $\sim 60 \%$ of patients who die of a pulmonary embolism [8]. Landmark angiographic studies showed that pulmonary artery pressure increases when thromboemboli occlude more than $30-50 \%$ of the total cross-sectional area of the pulmonary arterial bed [9]. Several studies have suggested that the correlation between the extent of mechanical embolic obstruction and the degree of pulmonary hypertension is relatively modest [10]. Indeed, pulmonary embolism with obstruction of only $25 \%$ of the pulmonary vascular tree can cause marked pulmonary hypertension, while wider obstructions can cause only slight increases in pulmonary arterial pressure [11]. This is consistent with more recent data on the assessment of the burden of emboli by computed tomography (CT) angiography. By using this imaging technique, a moderate correlation was found between the burden of embolic obstruction and right ventricular dilation or other indirect signs of pulmonary hypertension $[12,13]$ but no correlation was found between the extent of embolic obstruction and all-cause death or clinical deterioration [14]. A correlation has been claimed between the localisation of emboli and all-cause death or clinical deterioration in haemodynamically stable patients (localisation in the main pulmonary arteries: hazard ratio $8.3,95 \%$ CI 1.0-67; localisation in segmental or subsegmental branches: hazard ratio $0.12,95 \%$ CI $0.015-0.97$ ) [14]. The prominent prognostic value of proximal location of emboli for the overall burden of embolic obstruction is intriguing, as the cross-sectional size of the pulmonary vasculature increases exponentially from the main pulmonary artery to the subsegmental level. Whether the apparent discordance between the burden of obstruction and the degree of pulmonary hypertension can be partially explained by pre-existing cardiopulmonary diseases is unclear.

In addition to mechanical obstruction, vasoconstriction of the pulmonary arterial bed secondary to hypoxia seems to contribute to pulmonary hypertension in acute pulmonary embolism [15]. Thromboxane $\mathrm{A}_{2}$ and serotonin have been reported to be among the principal mediators of pulmonary artery vasoconstriction [16]. Limited data on the role of neurohumorally mediated vasoconstriction and on the clinical benefit of its reversal are available in humans [17-20].

As a non-preconditioned, thin-walled right ventricle is unable to overcome a mean pulmonary artery pressure $>40 \mathrm{mmHg}$, the rapid rise in afterload results in right ventricular dilation (fig. 1). Dilation alters the contractile properties of the right ventricle, and leads to an increase in wall tension and myocyte stretch. As a consequence of dilation, right ventricular contraction time is prolonged and this could result in paradoxical interventricular septal motion [21] and, eventually, in a marked reduction of left ventricular filling. The consequent reduction of the cardiac output further contributes to the onset of systemic hypotension and haemodynamic instability [22]. The stretching of the right ventricle due to the pressure overload is associated with an elevation in circulating levels of biomarkers of myocardial injury. The imbalance between oxygen supply and demand can damage cardiomyocytes and further reduce right ventricular function.

\section{Relationship between pathophysiology and risk of in-hospital death}

Acute pulmonary embolism has a wide spectrum of clinical presentation, severity and outcome, and advocates risk stratification to assess the severity of the event and to tailor clinical management [2, 23]. Several studies have been conducted in order to correlate the pathophysiology of the pulmonary circulation to the clinical course of acute pulmonary embolism. 

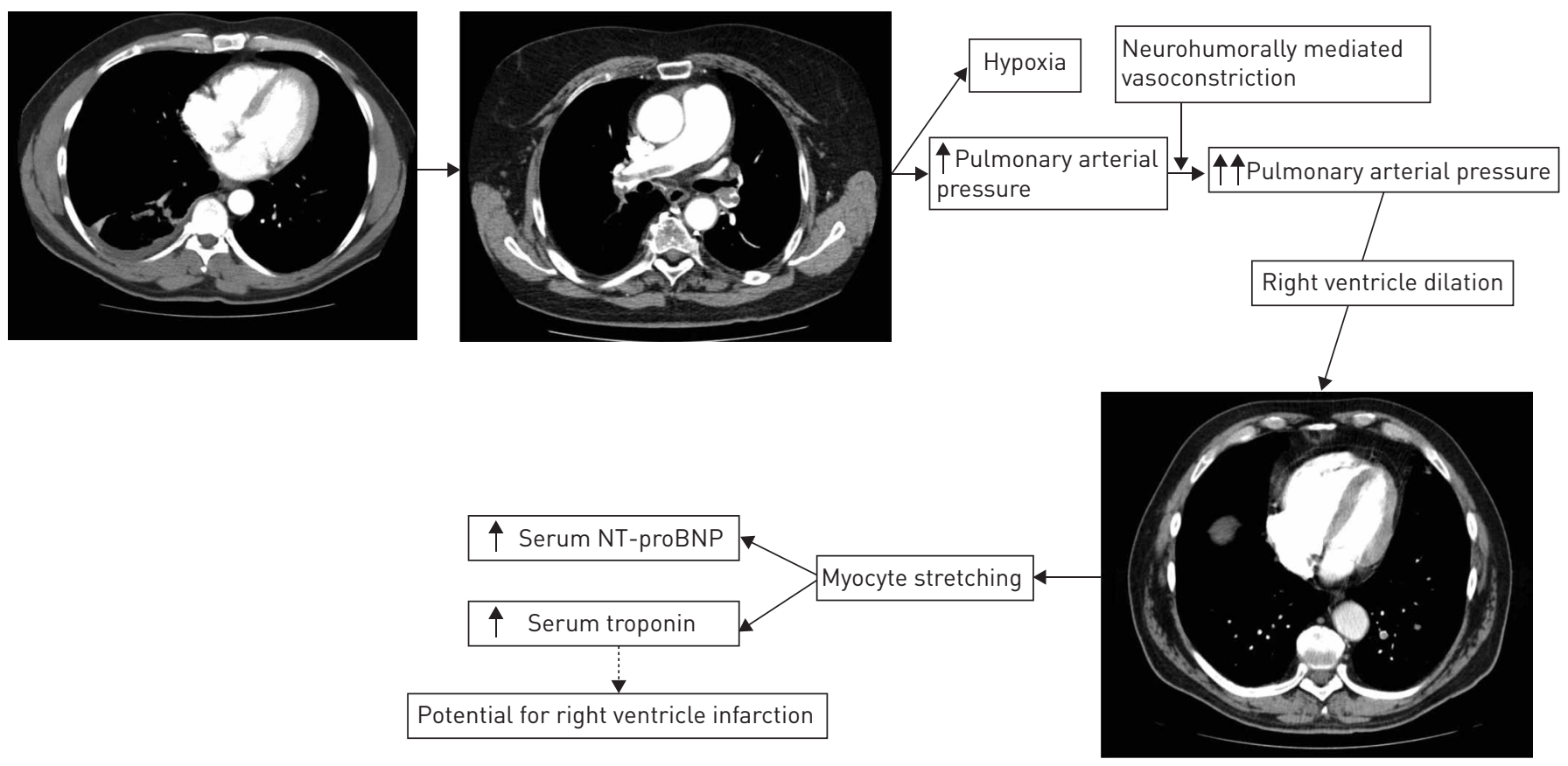

FIGURE 1 Pathophysiology of pulmonary embolism. NT-proBNP: N-terminal pro-brain natriuretic peptide.

Severe right heart failure with low-output syndrome inducing shock or sustained hypotension identifies patients with severe pulmonary embolism who are regarded as being at "high risk" or affected by "massive" pulmonary embolism; in these patients in-hospital mortality can be as high as $15-30 \%$ [2, 23].

In haemodynamically stable patients, risk stratification can be initially performed through the use of clinical models [24]. An association between pre-existing chronic pulmonary diseases (e.g. chronic obstructive pulmonary disease) or chronic heart failure and mortality has been described in patients with acute pulmonary embolism [5]. These conditions have been included in clinical models for the assessment of short-term mortality [25]. As suggested by the recent guidelines of the European Society of Cardiology (ESC), the assessment of right ventricle dysfunction and injury could be avoided in haemodynamically stable patients at low risk of death according to these clinical models (fig. 2) [24].

In patients with acute pulmonary embolism, right ventricular dilation can be sought by echocardiography but can also be found by CT performed for diagnostic purposes [26]. Right ventricular dilation, as assessed by either echocardiography (OR 2.4, 95\% CI 1.3-4.3) or CT (OR 2.08, 95\% CI 1.63-2.66), is associated with an increased risk of death $[27,28]$. Patients with pulmonary embolism and increased levels of biomarkers of myocardial injury, mainly troponin (OR 5.24, 95\% CI 3.28-8.38), also have an increased risk for death even in the absence of haemodynamic impairment (OR 5.90, 95\% CI 2.68-12.95) [29]. The risk of death or clinical deterioration in haemodynamically stable patients with evidence of both right ventricular dysfunction and injury is further increased (hazard ratio 14.2, 95\% CI 1.94-104.16) [30]. Thus, in the recent ESC guidelines, haemodynamically stable patients with evidence of both right ventricular dysfunction and injury are indicated as patients at intermediate-high risk of death, while those with none or only one of these are at intermediate-low risk [24].

Despite remarkable evidence, translating the correlation between pathophysiology and clinical outcome to clinical management of patients with acute pulmonary embolism is challenging. The potential for home treatment or short hospitalisation for patients with a low risk of pulmonary embolism needs to be confirmed in further randomised clinical trials. The need for treatment upgrading for patients at intermediate-high risk of death has been only partially shown by randomised clinical trials, as thrombolytic therapy reduces the rate of in-hospital clinical deterioration but not mortality [24-31].

\section{Anticoagulant treatment for acute pulmonary embolism}

The anticoagulant treatment of pulmonary embolism includes three phases: initial, long-term and extended treatments $[24,32]$. The goals of treatment are to reduce mortality and early recurrence for initial anticoagulation (first 5-10 days), and to reduce late recurrences for the long term (mostly 36 months) and extended anticoagulation (beyond the first 3-6 months). 
FIGURE 2 Expected prevalence (blue) of and short-term mortality (red) in different risk categories of pulmonary embolism according to the European Society of Cardiology risk stratification scheme. HD: haemodynamically; RVD: right ventricular dysfunction.

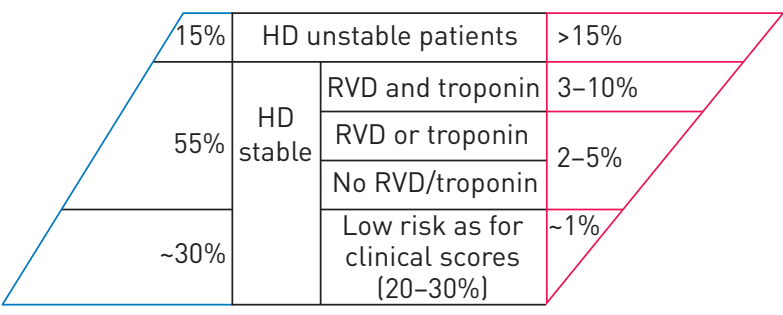

Prevalence
Risk category mortality

Anticoagulant treatment with unfractionated heparin reduces 2 -week mortality by $\sim 70 \%$ compared with no treatment [33]. In patients with pulmonary embolism, weight-adjusted low-molecular-weight heparin is associated with a statistically nonsignificant decrease in recurrent symptomatic venous thromboembolism ( $1.4 \%$ versus $2.4 \%$; OR $0.63,95 \%$ CI $0.33-1.18$ ) and major bleeding ( $1.4 \%$ versus $2.3 \%$; OR $0.67,95 \%$ CI 0.36-1.27) in comparison to activated partial thromboplastin time-adjusted unfractionated heparin [34]. No difference in all-cause mortality (1.4\% versus $1.2 \%$; OR $1.20,95 \%$ CI $0.59-2.45)$ has been reported between the two treatment strategies [34].

Fondaparinux, the pentasaccharide sequence responsible for the anti-factor Xa activity of heparin, given subcutaneously once daily, has been shown to be as effective (absolute difference of $-1.2 \%, 95 \%$ CI $-3.0-$ $0.5 \%)$ and safe as unfractionated heparin for the initial treatment of patients with symptomatic, objectively confirmed pulmonary embolism [35]. Idraparinux, a long-acting inhibitor of activated factor X given subcutaneously once weekly, was compared with heparin followed by vitamin $\mathrm{K}$ antagonists in a randomised, open-label, noninferiority trial in 2215 patients with pulmonary embolism [36]. Idraparinux did not meet the noninferiority requirement for efficacy as the incidence of recurrence was 3.4 and $1.6 \%$ in the idraparinux and in the conventional treatment group, respectively (OR 2.14, 95\% CI 1.21-3.78). Although the higher risk of recurrence observed in patients randomised to treatment with idraparinux persisted up to the end of the study (180 days), it was deemed to be mainly related to a potential under-anticoagulation in the acute phase. The renewed attention to intensity of anticoagulation in the acute phase mainly influenced the clinical development of newer anticoagulants, leading to the design of regimens with high intensities of anticoagulation or with heparin pre-treatment in the acute phase.

Thrombolytic therapy given on the top of anticoagulation achieves faster pulmonary reperfusion, as detected by both conventional pulmonary angiography and lung scintigraphy. A meta-analysis of studies including haemodynamically unstable patients showed a $50 \%$ reduction in recurrent pulmonary embolism or death compared with heparin alone (9.4\% versus $19.0 \%$; OR 0.45 , 95\% CI $0.22-0.92$; number needed to treat, 10 ) [37]. In a more recent meta-analysis, thrombolytic therapy was associated with a significant reduction in overall mortality compared with heparin (OR 0.59, 95\% CI 0.36-0.96) [38]. This reduction was not statistically significant after exclusion of studies including high-risk pulmonary embolism (OR 0.64, 95\% CI 0.35-1.17).

Long-term treatment up to $\geqslant 3$ months after the acute pulmonary embolism is required in all patients to stabilise the results obtained in the initial phase of treatment and should be regarded as a continuum of the acute-phase treatment [39]. Oral vitamin K antagonists have been the drugs of choice for this phase of treatment for their efficacy and for the potential of oral administration. In patients with cancer-associated venous thromboembolism, long-term treatment with low-molecular-weight heparin should be preferred over vitamin $\mathrm{K}$ antagonists.

\section{Direct oral anticoagulants}

Two classes of new oral anticoagulants have been developed to overcome the limits of conventional anticoagulation: anti-Xa (rivaroxaban, apixaban and edoxaban) and antithrombin (dabigatran) agents [40]. All these agents are synthetic low-molecular-weight compounds that act as direct, selective and reversible inhibitors of a specific step in the coagulation cascade [41-47]. The anticoagulant effect of these agents is more predictable compared to that of heparin or vitamin $\mathrm{K}$ antagonists, allowing their administration in fixed doses without the need for laboratory monitoring or dose adjustment. The short half-lives of the new agents could make clinical management of situations requiring reversal of anticoagulation (need for invasive procedures and bleeding) easier.

\section{Direct oral anticoagulants for acute pulmonary embolism}

New oral anticoagulants have been compared to conventional anticoagulation for the initial and long-term treatment of venous thromboembolism, and to placebo or warfarin for the extended treatment of this 
disease. Patients with pulmonary embolism with haemodynamic instability or requiring thrombolytic therapy were excluded from these studies.

EINSTEIN-PE is the only trial that exclusively included patients presenting with acute pulmonary embolism. In this trial, rivaroxaban was compared with conventional anticoagulant treatment (enoxaparin or fondaparinux followed by vitamin $\mathrm{K}$ antagonists). Both treatments were given for 3, 6 or 12 months at discretion of the attending physician [48]. This randomised, open-label, noninferiority trial included 4832 patients with acute pulmonary embolism. Rivaroxaban was given at the dose of $15 \mathrm{mg}$ twice daily for 3 weeks followed by $20 \mathrm{mg}$ once daily thereafter without heparin pre-treatment. The regimen of rivaroxaban was derived from evidence obtained from phase II studies in patients with acute deep vein thrombosis [49]. Recurrent venous thromboembolism occurred in $2.1 \%$ and $1.8 \%$ of the patients with rivaroxaban and conventional therapy, respectively (hazard ratio 1.12, 95\% CI 0.75-1.68; non-inferiority $\mathrm{p}=0.003$ ). The primary safety outcome of major or clinically relevant non-major bleeding occurred in $10.3 \%$ and $11.4 \%$ of patients in the rivaroxaban or conventional therapy group, respectively, but major bleeding was significantly lower in patients receiving rivaroxaban than in patients receiving enoxaparin/ vitamin $\mathrm{K}$ antagonists ( $1.1 \%$ versus $2.2 \%$, respectively; hazard ratio $0.49,95 \%$ CI $0.31-0.79$; $\mathrm{p}=0.003$ ).

Patients with acute pulmonary embolism constituted about one-third of the patients included in phase III trials with dabigatran, apixaban and edoxaban for the treatment of venous thromboembolism.

RE-COVER I and II were double-blind, double-dummy trials in which patients with acute deep vein thrombosis and/or pulmonary embolism were randomised to 6 months treatment with dabigatran (150 mg twice daily) or warfarin after an initial heparin treatment given for a median of 9 days [50, 51]. In the pooled analysis of the RE-COVER I and II studies, 1602 patients had pulmonary embolism at time of inclusion in the studies [51]. In these patients, recurrent nonfatal or fatal venous thromboembolism occurred in $2.2 \%$ versus $2.6 \%$ of those randomised to dabigatran or warfarin, respectively, confirming similar treatment effects of dabigatran compared with warfarin in this subgroup of patients and in the overall study population (hazard ratio $1.08,95 \%$ CI $0.64-1.80$ in the overall study population; p-value for interaction 0.36 for index pulmonary embolism).

In the Apixaban for the Initial Management of Pulmonary Embolism and Deep-Vein Thrombosis as First-Line Therapy (AMPLIFY) study, 5395 patients with acute symptomatic proximal deep vein thrombosis or acute symptomatic pulmonary embolism were randomised to either initial treatment with apixaban (10 mg twice daily for 7 days followed by $5 \mathrm{mg}$ twice daily) or standard treatment with enoxaparin followed by vitamin $\mathrm{K}$ antagonists for 6 months in a double-blind fashion [52]. On inclusion in the study, 1836 patients had symptomatic, objectively confirmed pulmonary embolism. Among these patients, recurrent symptomatic venous thromboembolism or death related to venous thromboembolism occurred in $2.3 \%$ and in $2.6 \%$ of those randomised to apixaban or conventional therapy (relative risk 0.90, 95\% CI 0.50-1.61).

Edoxaban $60 \mathrm{mg}$ once daily (30 mg daily in patients with risk of overdose) was compared with dose-adjusted warfarin in patients with symptomatic deep vein thrombosis (4921 patients) or pulmonary embolism (3319 patients) in a double-blind, double-dummy clinical trial after all patients received an initial 5-day treatment with heparin [53]. Treatment duration was pre-specified based on patients' individual risk as 3, 6 or 12 months. Among patients with index pulmonary embolism randomised to edoxaban or warfarin, recurrent venous thromboembolism and related deaths occurred in $2.8 \%$ versus $3.9 \%$, respectively (OR $0.73,95 \%$ CI $0.50-1.06$ ).

\section{Direct oral anticoagulants and risk stratification in acute pulmonary embolism}

Whether the results obtained with direct oral anticoagulants in the treatment of acute pulmonary embolism apply to all patients with intermediate pulmonary embolism is unclear. These patients, identified through the presence of right ventricle dysfunction and increase in serum troponin, represents from $30 \%$ to $>50 \%$ of the entire population with pulmonary embolism $[26,30,54]$. Data on right ventricle dysfunction and injury are not available in patients included in most of phase III trials. In these studies, the severity assessment of pulmonary embolism was mainly based on the thrombotic burden at CT (table 1).

According to the anatomical extent of pulmonary embolism, about one-quarter of the patients included in the EINSTEIN-PE had extensive (involvement of multiple lobes and $>25 \%$ of entire pulmonary vasculature), $\sim 58 \%$ had intermediate and $\sim 12 \%$ had limited ( $\leqslant 25 \%$ of vasculature of a single lobe) pulmonary embolism [48]. The noninferiority of rivaroxaban compared with conventional anticoagulation was consistent in three tertiles of severity of pulmonary embolism in the subgroup analysis. However, the criteria for tertile identification were not reported.

In the AMPLIFY study, about one-third of patients with pulmonary embolism had extensive pulmonary embolism as assessed by the thrombotic burden at CT (multiple lobes and $>25 \%$ of entire pulmonary 
TABLE 1 Noninferiority clinical trials with direct oral anticoagulants for the acute and long-term therapy of pulmonary embolism (PE)

\begin{tabular}{|c|c|c|c|c|c|c|}
\hline Drug & Trial & Design & Treatments & Duration & Patients & $\begin{array}{l}\text { Severity evaluation } \\
\text { for PE }\end{array}$ \\
\hline Rivaroxaban & EINSTEIN-PE [48] & Open & $\begin{array}{l}\text { Rivaroxaban (15 mg twice } \\
\text { daily for } 3 \text { weeks, then } 20 \mathrm{mg} \\
\text { once daily) }\end{array}$ & $\begin{array}{c}3,6 \text { or } \\
12 \text { months }\end{array}$ & $\begin{array}{l}4832 \text { patients } \\
\text { with } \mathrm{PE}\end{array}$ & $\begin{array}{c}\text { Anatomical extension } \\
\text { of PE }\end{array}$ \\
\hline Apixaban & AMPLIFY [52] & $\begin{array}{l}\text { Double } \\
\text { blind }\end{array}$ & $\begin{array}{c}\text { Enoxaparin/warfarin } \\
\text { Apixaban (10 mg twice daily for } \\
7 \text { days, then } 5 \mathrm{mg} \text { twice daily) } \\
\text { Enoxaparin/warfarin }\end{array}$ & 6 months & $\begin{array}{l}1836 \text { patients } \\
\text { with } \mathrm{PE}\end{array}$ & $\begin{array}{c}\text { Tertiles of severity } \\
\text { Anatomical extension } \\
\text { of PE }\end{array}$ \\
\hline Edoxaban & HOKUSAI [53] & $\begin{array}{l}\text { Double } \\
\text { blind }\end{array}$ & $\begin{array}{l}\text { LMWH/edoxaban } 160 \mathrm{mg} \\
\text { once daily) } \\
\text { UFH or LMWH/warfarin }\end{array}$ & $<12$ months & $\begin{array}{l}3319 \text { patients } \\
\text { with } \mathrm{PE}\end{array}$ & $\begin{array}{l}\text { NT-proBNP levels } \\
\text { (2989 patients) } \\
\text { Right ventricle dilation } \\
\text { at CT (1002 patients) }\end{array}$ \\
\hline Dabigatran & $\begin{array}{c}\text { RE-COVER I and } \\
\text { RE-COVER II }[50,51]\end{array}$ & $\begin{array}{l}\text { Double } \\
\text { blind }\end{array}$ & $\begin{array}{c}\text { Enoxaparin/dabigatran }(150 \mathrm{mg} \\
\text { twice daily) } \\
\text { Enoxaparin/warfarin }\end{array}$ & 6 months & $\begin{array}{l}1602 \text { patients } \\
\text { with } \mathrm{PE}\end{array}$ & Not reported \\
\hline
\end{tabular}

AMPLIFY: Apixaban for the Initial Management of Pulmonary Embolism and Deep-Vein Thrombosis as First-Line Therapy; LMWH: low-molecular-weight heparin; UFH: unfractionated heparin; NT-proBNP: N-terminal pro-brain natriuretic peptide.

vasculature at CT) [52]. Efficacy and safety profiles of apixaban were confirmed in patients with different extents of vascular involvement ( $\mathrm{p}=0.0569$ for interaction on efficacy, not evaluable for safety).

In the HOKUSAI study, 2989 patients had the assessment of N-terminal pro-brain natriuretic peptide levels and 1002 the assessment of right ventricle dysfunction at CT. Increased N-terminal pro-brain natriuretic peptide levels were observed in 938 (31\%) patients [53]; the rate of recurrent venous thromboembolism in this subgroup was $3.3 \%$ with edoxaban and $6.2 \%$ with warfarin (hazard ratio 0.52 , 95\% CI 0.28-0.98). Right ventricular dysfunction, as assessed by means of CT, was present in $\sim 30 \%$ of the 1002 evaluated patients. In patients with right ventricular dysfunction at CT, a nonsignificant reduction in recurrent venous thromboembolism was observed with edoxaban as compared with warfarin (hazard ratio $0.42,95 \%$ CI $0.15-1.20)$.

No data are available for dabigatran in subgroups of patients with pulmonary embolism of different severity.

None of the phase III studies with the new oral anticoagulants was large enough to have sufficient power for subgrouping according to right ventricular dysfunction. Further studies should assess the efficacy and safety of direct oral anticoagulants in subgroups of patients with different risk for death (e.g. those with right ventricle dysfunction and/or injury).

Only preliminary evidence is currently available on the use of rivaroxaban in patients who have been treated with thrombolytic agents [55]. No data in this clinical setting are available with the other agents.

Recurrent venous thromboembolism can be reduced by extending anticoagulant treatment $[56,57]$.

Phase III studies have been conducted with rivaroxaban, apixaban or dabigatran versus placebo in the extended treatment of venous thromboembolism [58-60]. All these agents were shown to be superior to placebo in the prevention of recurrences with a relatively favourable safety profile in terms of major bleeds. Dabigatran was also shown to be as effective and safer than warfarin in this indication [60].

\section{Conclusions}

Risk stratification in patients with acute pulmonary embolism is essentially based on the pathophysiology of the disease, which is mainly reflected by haemodynamic status and right ventricular overload. Recent trials with new anticoagulants have demonstrated the efficacy and safety of these agents in haemodynamically stable patients with acute pulmonary embolism. However, data on the severity of pulmonary embolism in the included patients are limited. Further evidence is awaited on the efficacy and safety of direct oral anticoagulants for patients with acute pulmonary embolism based on currently recommended risk stratification models.

\section{References}

1 Anderson FA Jr, Wheeler HB, Goldberg RJ, et al. A population-based perspective of the hospital incidence and case-fatality rates of deep vein thrombosis and pulmonary embolism. The Worcester DVT Study. Arch Intern Med 1991; 151: 933-938. 
Torbicki A, Perrier A, Konstantinides S, et al. Guidelines on the diagnosis and management of acute pulmonary embolism: the Task Force for the Diagnosis and Management of Acute Pulmonary Embolism of the European Society of Cardiology (ESC). Eur Heart J 2008; 29: 2276-2315.

3 Fontana P, Goldhaber SZ, Bounameaux H. Direct oral anticoagulants in the treatment and long-term prevention of venous thrombo-embolism. Eur Heart J 2014; 35: 1836-1843.

4 Heit JA, Silverstein MD, Mohr DN, et al. Predictors of survival after deep vein thrombosis and pulmonary embolism: a population-based, cohort study. Arch Intern Med 1999; 159: 445-453.

5 Goldhaber SZ, Visani L, De Rosa M. Acute pulmonary embolism: clinical outcomes in the International Cooperative Pulmonary Embolism Registry (ICOPER). Lancet 1999; 353: 1386-1389.

6 Pollack CV, Schreiber D, Goldhaber SZ, et al. Clinical characteristics, management and outcomes of patients diagnosed with acute pulmonary embolism in the emergency department: initial report of EMPEROR (Multicenter Emergency Medicine Pulmonary Embolism in the Real World Registry). J Am Coll Cardiol 2011; 57: $700-706$.

7 McIntyre KM, Sasahara AA. The hemodynamic response to pulmonary embolism in patients without prior cardiopulmonary disease. Am J Cardiol 1971; 28: 288-294.

8 Orde MM, Puranik R, Morrow PL, et al. Myocardial pathology in pulmonary thromboembolism. Heart 2011; 97: $1695-1699$.

9 McIntyre KM, Sasahara AA. Determinants of right ventricular function and hemodynamics after pulmonary embolism. Chest 1974; 65: 534-543.

10 Miller RL, Das S, Anandarangam T, et al. Association between right ventricular function and perfusion abnormalities in hemodynamically stable patients with acute pulmonary embolism. Chest 1998; 113: 665-670.

11 Alpert JS, Godtfredsen J, Ockene IS, et al. Pulmonary hypertension secondary to minor pulmonary embolism. Chest 1978; 73: 795-797.

12 Furlan A, Aghayev A, Chang CC, et al. Short-term mortality in acute pulmonary embolism: clot burden and signs of right heart dysfunction at CT pulmonary angiography. Radiology 2012; 265: 283-293.

13 Apfaltrer P, Bachmann V, Meyer M, et al. Prognostic value of perfusion defect volume at dual energy CTA in patients with pulmonary embolism: correlation with CTA obstruction scores, CT parameters of right ventricular dysfunction and adverse clinical outcome. Eur J Radiol 2012; 81: 3592-3597.

14 Vedovati MC, Becattini C, Agnelli G, et al. Multidetector CT scan for acute pulmonary embolism: embolic burden and clinical outcome. Chest 2012; 142: 1417-1424.

15 Stratmann G, Gregory GA. Neurogenic and humoral vasoconstriction in acute pulmonary thromboembolism. Anesth Analg 2003; 97: 341-354.

16 Smulders YM. Pathophysiology and treatment of haemodynamic instability in acute pulmonary embolism: the pivotal role of pulmonary vasoconstriction. Cardiovasc Res 2000; 48: 23-33.

17 Huet Y, Brun-Buisson C, Lemaire F, et al. Cardiopulmonary effects of ketanserin infusion in human pulmonary embolism. Am Rev Respir Dis 1987; 135: 114-117.

18 Summerfield DT, Desai H, Levitov A, et al. Inhaled nitric oxide as salvage therapy in massive pulmonary embolism: a case series. Respir Care 2012; 57: 444-448.

19 Bates ER, Crevey BJ, Sprague FR, et al. Oral hydralazine therapy for acute pulmonary embolism and low output state. Arch Intern Med 1981; 141: 1537-1538.

20 Alsaghir AH, Alaithan SA, Alsihati B, et al. Iloprost in pulmonary hypertension due to sub-massive pulmonary embolism: report of two cases. Libyan J Med 2013; 8: 22391.

21 Marcus JT, Gan CT, Zwanenburg JJ, et al. Interventricular mechanical asynchrony in pulmonary arterial hypertension: left-to-right delay in peak shortening is related to right ventricular overload and left ventricular underfilling. J Am Coll Cardiol 2008; 51: 750-757.

22 Mauritz GJ, Marcus JT, Westerhof N, et al. Prolonged right ventricular post-systolic isovolumic period in pulmonary arterial hypertension is not a reflection of diastolic dysfunction. Heart 2011; 97: 473-478.

23 Jaff MR, McMurtry MS, Archer SL, et al. Management of massive and submassive pulmonary embolism, iliofemoral deep vein thrombosis, and chronic thromboembolic pulmonary hypertension: a scientific statement from the American Heart Association. Circulation 2011; 123: 1788-1830.

24 Konstantinides SV, Torbicki A, Agnelli G, et al. 2014 ESC Guidelines on the diagnosis and management of acute pulmonary embolism. Eur Heart J 2014; 35: 3033-3069.

25 Jiménez D, Aujesky D, Moores L, et al. Simplification of the pulmonary embolism severity index for prognostication in patients with acute symptomatic pulmonary embolism. Arch Intern Med 2010; 170: 1383-1389.

26 Becattini C, Agnelli G, Vedovati MC, et al. Multidetector computed tomography for acute pulmonary embolism: diagnosis and risk stratification in a single test. Eur Heart J 2011; 32: 1657-1663.

27 Coutance G, Cauderlier E, Ehtisham J, et al. The prognostic value of markers of right ventricular dysfunction in pulmonary embolism: a meta-analysis. Crit Care 2011; 15: R103.

28 Becattini C, Agnelli G, Germini F, et al. Computed tomography to assess risk of death in acute pulmonary embolism: a meta-analysis. Eur Respir J 2014; 43: 1678-1690.

29 Becattini C, Vedovati MC, Agnelli G. Prognostic value of troponins in acute pulmonary embolism: a meta-analysis. Circulation 2007; 116: 427-433.

30 Becattini C, Casazza F, Forgione C, et al. Acute pulmonary embolism: external validation of an integrated risk stratification model. Chest 2013; 144: 1539-1545.

31 Meyer G, Vicaut E, Danays T, et al. Fibrinolysis for patients with intermediate-risk pulmonary embolism. $N$ Engl $J$ Med 2014; 370: 1402-1411.

32 Kearon C, Akl EA, Comerota AJ, et al. Antithrombotic therapy for VTE disease: Antithrombotic Therapy and Prevention of Thrombosis, 9th ed: American College of Chest Physicians Evidence-Based Clinical Practice Guidelines. Chest 2012; 141: Suppl., e419S-e494S.

33 Barritt DW, Jordan SC. Anticoagulant drugs in the treatment of pulmonary embolism. A controlled trial. Lancet 1960; 1: 1309-1312.

34 Quinlan DJ, McQuillan A, Eikelboom JW. Low-molecular-weight heparin compared with intravenous unfractionated heparin for treatment of pulmonary embolism: a meta-analysis of randomized, controlled trials. Ann Intern Med 2004; 140: 175-183. 

in the initial treatment of pulmonary embolism. N Engl J Med 2003; 349: 1695-1702.

36 van Gogh Investigators, Buller HR, Cohen AT, et al. Idraparinux versus standard therapy for venous thromboembolic disease. N Engl J Med 2007; 357: 1094-1104.

37 Wan S, Quinlan DJ, Agnelli G, et al. Thrombolysis compared with heparin for the initial treatment of pulmonary embolism: a meta-analysis of the randomized controlled trials. Circulation 2004; 110: 744-749.

38 Marti C, John G, Konstantinides S, et al. Systemic thrombolytic therapy for acute pulmonary embolism: a systematic review and meta-analysis. Eur Heart J 2014 [In press DOI: 10.1093/eurheartj/ehu218].

39 Agnelli G, Becattini C. Acute pulmonary embolism. N Engl J Med 2010; 363: 266-274.

40 van der Hulle T, Kooiman J, den Exter PL, et al. Effectiveness and safety of novel oral anticoagulants as compared with vitamin $\mathrm{K}$ antagonists in the treatment of acute symptomatic venous thromboembolism: a systematic review and meta-analysis. J Thromb Haemost 2014; 12: 320-328.

41 Kubitza D, Becka M, Voith B, et al. Safety, pharmacodynamics, and pharmacokinetics of single doses of BAY 59-7939, an oral, direct factor Xa inhibitor. Clin Pharmacol Ther 2005; 78: 412-421.

42 Raghavan N, Frost CE, Yu Z, et al. Apixaban metabolism and pharmacokinetics after oral administration to humans. Drug Metab Dispos 2009; 37: 74-81.

43 Ahrens I, Bode C. Oral anticoagulation with edoxaban. Focus on current phase III clinical development. Hämostaseologie 2012; 32: 212-215.

44 Camm AJ, Bounameaux H. Edoxaban: a new oral direct factor Xa inhibitor. Drugs 2011; 71: $1503-1526$.

45 Sorbera LA, Bozzo J, Castaner J. Dabigatran/dabigatran etexilate. Drugs Fut 2005; 30: 877-885.

46 Stangier J, Eriksson BI, Dahl OE, et al. Pharmacokinetic profile of the oral direct thrombin inhibitor dabigatran etexilate in healthy volunteers and patients undergoing total hip replacement. J Clin Pharmacol 2005; 45: 555-563.

47 Walenga JM, Adiguzel C. Drug and dietary interactions of the new and emerging oral anticoagulants. Int $J$ Clin Pract 2010; 64: 956-967.

48 EINSTEIN-PE Investigators, Büller HR, Prins $\mathrm{MH}$, et al. Oral rivaroxaban for the treatment of symptomatic pulmonary embolism. N Engl J Med 2012; 366: 1287-1297.

49 Agnelli G, Gallus A, Goldhaber SZ, et al. Treatment of proximal deep-vein thrombosis with the oral direct factor Xa inhibitor rivaroxaban (BAY 59-7939): the ODIXa-DVT (Oral Direct Factor Xa Inhibitor BAY 59-7939 in Patients with Acute Symptomatic Deep-Vein Thrombosis) study. Circulation 2007; 116: 180-187.

50 Schulman S, Kearon C, Kakkar AK, et al. Dabigatran versus warfarin in the treatment of acute venous thromboembolism. N Engl J Med 2009; 361: 2342-2352.

51 Schulman S, Kakkar AK, Goldhaber SZ, et al. Treatment of acute venous thromboembolism with dabigatran or warfarin and pooled analysis. Circulation 2014; 129: 764-772.

52 Agnelli G, Buller HR, Cohen A, et al. Oral apixaban for the treatment of acute venous thromboembolism. $N$ Engl $J$ Med 2013; 369: 799-808.

53 Hokusai-VTE Investigators, Büller $\mathrm{HR}$, Décousus $\mathrm{H}$, et al. Edoxaban versus warfarin for the treatment of symptomatic venous thromboembolism. N Engl J Med 2013; 369: 1406-1415.

54 Scridon T, Scridon C, Skali H, et al. Prognostic significance of troponin elevation and right ventricular enlargement in acute pulmonary embolism. Am J Cardiol 2005; 96: 303-305

55 Sharifi M, Bay C, Schwartz F, et al. Safe-dose thrombolysis plus rivaroxaban for moderate and severe pulmonary embolism: drip, drug, and discharge. Clin Cardiol 2014; 37: 78-82.

56 Agnelli G, Prandoni P, Becattini C, et al. Extended oral anticoagulant therapy after a first episode of pulmonary embolism. Ann Intern Med 2003; 139: 19-25.

57 Boutitie F, Pinede L, Schulman S, et al. Influence of preceding length of anticoagulant treatment and initial presentation of venous thromboembolism on risk of recurrence after stopping treatment: analysis of individual participants' data from seven trials. BMJ 2011; 342: d3036.

58 Bauersachs R, Berkowitz SD, Brenner B, et al. Oral rivaroxaban for symptomatic venous thromboembolism. N Engl J Med 2010; 363: 2499-2510.

59 Agnelli G, Buller HR, Cohen A, et al. Apixaban for extended treatment of venous thromboembolism. $N$ Engl J Med 2012; 368: 699-708.

60 Schulman S, Kearon C, Kakkar AK, et al. Extended use of dabigatran, warfarin, or placebo in venous thromboembolism. N Engl J Med 2013; 368: 709-718. 